\title{
A Construção de Objetos de Aprendizagem para o Ensino de Sociologia no Ensino Médio
}

\author{
Vinicius Hartmann Ferreira, Vanessa Petró, Luís Guilherme Eich, Murillo \\ Weissheimer, Fernando Zanutto, Alecsander Hennig
}

\author{
Instituto Federal de Educação, Ciência e Tecnologia do Rio Grande do Sul - Campus \\ Feliz \\ Feliz - RS - Brasil \\ vinihf@gmail.com, vanessapetro@gmail.com, gui.eich@hotmail.com, \\ weiss.muri@gmail.com, ferzanutto1999@gmail.com, \\ hennig.alecsander@gmail.com
}

\begin{abstract}
After reinsertion of Sociology's discipline in high school curriculum their curriculum and their practices in the classroom has been discussed in events and research groups. A survey about the practices in the discipline presents the existence of a few interactive features, especially of digital learning objects (LO). This article presents an experience that is being developed for the construction of LOs that began in 2014, whose goal is to help students work out and understand the contents studied. Resources are developed from the demand presented by the students of a school that offer the Technical Course in Computing integrated with high school and are designed and implemented with the collaboration of scholarship students from that course through a research project that integrates the areas of Sociology and Computer Science.
\end{abstract}

Resumo. Após a reinserção da disciplina de Sociologia no currículo do Ensino Médio, tem se discutido sobre seu currículo e suas práticas em sala de aula em eventos e grupos de pesquisa. Um levantamento realizado sobre as práticas na disciplina aponta para a existência de poucos recursos interativos, sobretudo de Objetos de Aprendizagem digitais (OA). Este artigo apresenta uma experiência que está sendo desenvolvida para a construção de OAs que se iniciou em 2014, cujo objetivo é auxiliar os estudantes a exercitar e fixar os conteúdos estudados. Os recursos são desenvolvidos a partir da demanda apresentada pelos estudantes de uma escola que oferta o Curso Técnico em Informática Integrado ao Ensino Médio e são concebidos e executados com a colaboração de estudantes bolsistas do referido curso por meio de um projeto de pesquisa que integra as áreas de Sociologia e de Informática.

\section{Introdução}

Após idas e vindas no currículo do ensino médio, a disciplina de Sociologia voltou a ser reinserida em 2008 como disciplina obrigatória, a partir do momento em que foi sancionada a lei 11.684. O ensino de Sociologia no nível médio enfrenta inúmeros desafios, como a precária formação dos professores, incluindo que de maneira recorrente os titulares da disciplina não têm formação na área de Ciências Sociais; a alta carga horária dos professores da rede pública estadual e os baixos salários (PEREIRA, 2009).

Acrescenta-se a estes desafios os fatos de que a disciplina de Sociologia exige dos estudantes para sua compreensão a capacidade de abstração, uma capacidade que muitos estudantes de ensino médio apresentam deficiência, e a falta de recursos que 
possam auxiliar os estudantes com esta dificuldade. Ainda que para a disciplina existam livros didáticos, filmes e documentários, músicas e imagens, poucos são os recursos que permitem ao aluno interagir com o conteúdo e fazer relações entre os conceitos estudados e o seu cotidiano. É neste contexto que recursos digitais interativos, como Objetos de Aprendizagem (OA), podem contribuir para a disciplina de Sociologia (FERREIRA, PETRÓ e EICH, 2015).

Este artigo apresenta um projeto desenvolvido em conjunto entre as disciplinas de Programação e de Sociologia de um curso técnico em informática integrado ao ensino médio. Neste projeto, que se iniciou em 2014, OAs são construídos por alunos do curso a partir das demandas identificadas pela professora da disciplina de Sociologia e dos alunos durante os anos letivos. Este artigo está organizado de forma a apresentar os conceitos que fundamentam a pesquisa na Seção 2, os OAs desenvolvidos e os resultados alcançados na Seção 3 e as conclusões obtidas na Seção 4.

\section{Sociologia no Ensino Médio e os Objetos de Aprendizagem}

Um OA é qualquer recurso digital que tenha conteúdo educacional e propósito de aprendizagem e que possa ser usado e reutilizado em diferentes contextos (SILVEIRA e CARNEIRO, 2012; WILEY, 2000). Um OA pode ter seu foco em diferentes áreas de conhecimento e ser composto por um ou mais recursos de diferentes formatos, como textos, vídeos, músicas, animações ou jogos.

Em uma busca feita em eventos e periódicos científicos nacionais, tanto da área de Informática na Educação quanto de Sociologia, poucas produções foram encontradas com foco no uso ou produção de recursos digitais interativos para a disciplina de Sociologia. A maioria dos trabalhos relata a utilização de filmes ou documentários e imagens, ou apresenta propostas de metodologias de ensino que utilizem recursos já existentes e que não se caracterizam como interativos (PEREIRA, 2009; LEITE, HUBLER e JUNIOR, 2013).

Os OAs podem se constituir como recursos relevantes para o ensino de Sociologia no nível médio. Entre os conteúdos previstos para esta disciplina estão conceitos teóricos que precisam ser relacionados com o mundo objetivo, além de acontecimentos históricos e pensadores que contribuíram para a formação da Sociologia enquanto ciência, o que também é conteúdo a ser trabalhado em sala de aula.

\section{Objetos de Aprendizagem para Sociologia}

No início do projeto, em 2014, verificou-se que os alunos apresentavam dificuldades com o conteúdo do $1^{\circ}$ ano, relacionado aos pensadores clássicos da Sociologia. Partindo da identificação deste conteúdo, buscou-se definir qual seria o melhor recurso para esta situação em reuniões que contavam com a participação dos professores da disciplina de Programação e de Sociologia e também de um aluno do curso que participava do projeto. Após o refinamento do conteúdo que deveria ser tratado relacionado aos pensadores clássicos, concluiu-se que seria desenvolvido um OA que consistia em uma linha do tempo na qual os alunos deveriam relacionar os pensadores de forma cronológica com suas principais contribuições para a Sociologia (Figura 1). 


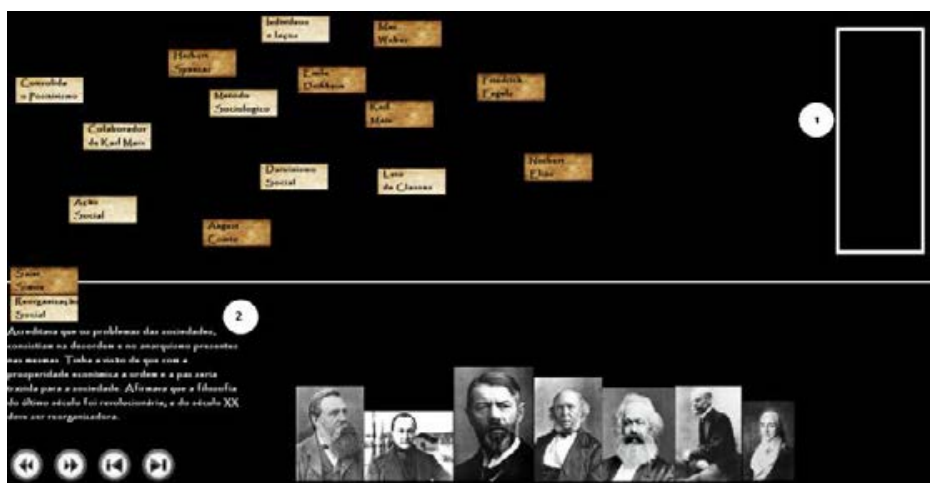

Figura 1. Tela principal do OA Linha do Tempo para Sociologia.

O OA foi desenvolvido de forma que os professores possam inserir informações sobre diferentes pensadores, tornando-o reutilizável, e possui dois módulos, o de atividade, no qual são apresentadas em cor vermelha as relações incorretas e em cor verde as relações corretas, e o de avaliação, no qual é apresentada a pontuação obtida pelos alunos com as relações corretas (Figura 2).



Figura 2. Módulo de atividade do OA Linha do Tempo para Sociologia.

Um experimento foi conduzido com o intuito de avaliar a receptividade dos alunos ao OA. Este experimento foi realizado por 40 alunos de uma turma de $1^{\circ}$ ano de ensino médio de um curso técnico em informática integrado. Os alunos utilizaram o recurso na modalidade de avaliação e de atividade durante uma aula de Sociologia. Ao final, responderam um questionário que permitiu identificar, dentre outros aspectos, que o recurso os auxiliou a organizar o pensamento sobre o conteúdo trabalhado (FERREIRA, PETRÓ e EICH, 2015).

No ano de 2015 o projeto iniciou a construção de um novo OA, que tem previsão de conclusão até o final do $1^{\circ}$ semestre de 2016. Este novo recurso também está sendo desenvolvido por alunos do curso técnico em informática integrado ao ensino médio e possui fundamentos relacionados à mecânica de jogos. O novo recurso tem por objetivo trabalhar conceitos relacionados às ideologias políticas e à forma como os atores políticos lidam com as mesmas no parlamento.

Neste novo recurso o estudante assume a presidência de um país fictício e deve inicialmente indicar se sua ideologia será voltada para "o bem estar" ou para o neoliberalismo, o que é associado a ideologias de esquerda e de direita no espectro político. A partir desta escolha o estudante deve tomar decisões que afetam indicadores como saúde, educação, economia e segurança. Cada decisão implicará na inclinação de um termômetro que indica a qual das ideologias estão relacionadas suas decisões (Figura 3). Também está em desenvolvimento neste OA um mecanismo que permitirá ao estudante solicitar opinião aos seus conselheiros, que também têm partido e 
ideologias próprias. No momento dessa consulta será possível identificar elementos para além das ideologias que exercem influência no posicionamento político, tais como os interesses pragmáticos e privados, as relações pessoais, as trocas de favores, dentre outros.

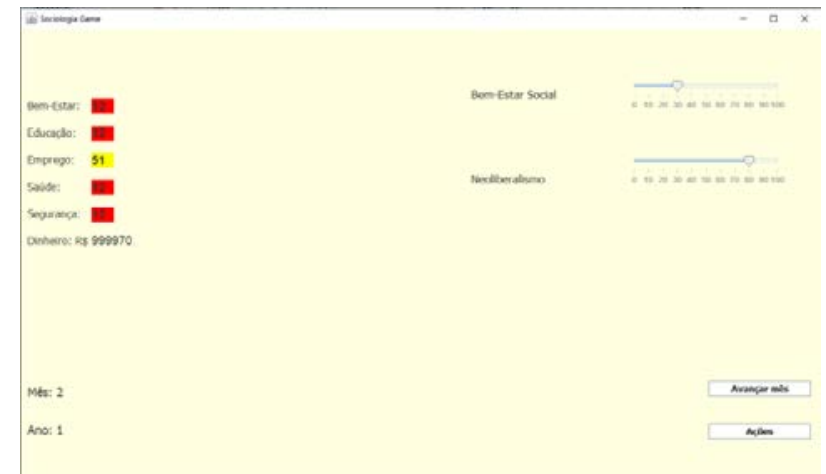

Figura 3. Tela de administração do país com indicadores da ideologia adotada.

\section{Conclusão}

Este artigo apresentou os resultados de um projeto interdisciplinar que envolve as disciplinas de Sociologia e de Programação de um curso técnico em informática integrado ao ensino médio. Até o momento foi desenvolvido um OA, intitulado Linha do Tempo para Sociologia e disponível para download em http://vhflabs.com.br/projetos.html, que foi utilizado por alunos de uma turma de $1^{\circ}$ ano do ensino médio em um experimento que indicou boa aceitação.

Um novo OA está sendo desenvolvido com foco em conteúdos como ideologias políticas. Após sua conclusão pretende-se realizar um experimento com as turmas do $3^{\circ}$ ano do ensino médio com o intuito de verificar a recepção deles ao novo recurso e avaliar possíveis contribuições na compreensão dos conteúdos.

\section{Referências}

FERREIRA, V. H.; PETRÓ, V.; EICH, L. G. Um objeto de aprendizagem para a disciplina de sociologia no ensino médio. RENOTE - Revista Novas Tecnologias na Educação, Porto Alegre, v. 13, n. 1, p. 1-10, dez. 2015.

LEITE, C. A. C.; HUBLER, P. N.; JUNIOR, A. C. G. R. A inovação no ensino de sociologia com a utilização de objetos de aprendizagem. In: CONGRESSO BRASILEIRO DE SOCIOLOGIA, 16, 2013, Salvador. Anais... Salvador: SBS. 2013.

PEREIRA, T. I. Para além do senso comum: aportes para a construção do conhecimento sociológico na educação básica. In: CONGRESSO BRASILEIRO DE SOCIOLOGIA, 14, 2009, Rio de Janeiro. Anais... Rio de Janeiro: Sociedade Brasileira de Sociologia, 2009.

SILVEIRA, M. S.; CARNEIRO, M. L. F. Desconstruindo objetos de aprendizagem: reflexões sobre sua qualidade de uso. In: SIMPÓSIO BRASILEIRO DE INFORMÁTICA NA EDUCAÇÃO, 23, 2012, Rio de Janeiro. Anais... Rio de Janeiro: Sociedade Brasileira de Computação, 2012.

WILEY, D. A. Learning object design and sequencing theory. Provo, Utah: Department Of Instructional Psychology And Technology/Brigham Young University, 2000. 131p. Tese de Doutorado. 